\title{
THE FORMATION OF PERYLENEQUINONES IN ETIOLATED CUCUMBER SEEDLINGS INFECTED WITH CLADOSPORIUM CUCUMERINUM
}

\author{
J. C. Oveream and A. Kans SuPEsteis \\ Institute for Organic Chemistry TNO, Utrecht \\ and A. Fucks \\ Laboratory of Phytopathology, Agricultural University, Wageningen, The Netherlands
}

(Received 27 Aprll 1960)

\begin{abstract}
Abtract-Etiolated cucumber seedlings respond to infection by Cladosporium cucumerinum with the synthesis of wine-red pigments. Isolation and purification procedures for these pigments are described. They must be considered as derivatives of 4,9-dihydroxyperylene-3,10-quinone. On the basis of microanalyses, ultraviolet, infrared and nuclear magnetic resonance spectra a more detailed structural formula for the major pigment is tentatively proposed.
\end{abstract}

\section{INTRODUCTION}

CUCUMBer seedlings grown in the dark are as susceptible to the parasite Cladosporium cucumerinum as normal green seedlings. Whereas on the latter greyish spots develop 4 to 5 days after infection, etiolated seedlings show a peculiar wine-red discoloration on cotyledons and hypocotyls as the disease develops.

The present study was undertaken, since it was hoped that a closer investigation of this phenomenon and elucidation of the structure of the red product might throw some light on the host-parasite relation in cucumber scab.

\section{Formation of the Red Product}

\section{RESULTS}

The most satisfactory way to produce the red material was to spray 3-5-day-old seedlings, growing in sand in the dark, with a dense spore suspension of C. cucumerinum. Cucumber plants var. "Lange gele tros" were used. After a further 5 days in the dark the long hypocotyls had become dark red, especially in the higher parts, and the leaves showed red spots. The red coloured substance could be easily extracted with various organic solvents.

Extraction of green seedlings 5 days after infection with C. cuctumerinum did not yield the red product, nor did green or etiolated cucumber seedlings which had been infected with the parasites Corynespora melonis or Colletotrichum lagenarium give rise to a red compound after development of the disease. Neither were several non-parasitic fungi sprayed on to etiolated or green seedlings able to evoke the red colour. The cucumber variety Vios which is resistant to $C$. cucumerinum is slightly susceptible when grown in the dark; only small red spots develop.

Green or etiolated healthy seedlings never showed this discoloration, nor did incubation after squeezing or deep-freezing of the tissues produce it. By this latter procedure the latent 
polyphenoloxidase of cucumber seedlings is activated; diseased seedlings in contrast to healthy seedlings contain always an active polyphenoloxidase. ${ }^{1}$

On the other hand when $C$. cucumerinum was grown on a variety of media differing in composition of $\mathrm{C}$ - and $\mathrm{N}$-source and in $\mathrm{pH}$, or on Seitz filtered sap pressed from etiolated cucumbers, no red compound was formed.

The results obtained suggest that the formation of the red colour is closely related to the attack of etiolated cucumber seedlings by $C$. cucumerinum. The plants have, moreover, to be intact since lightly squeezed tissues incubated with pregrown pellets of the fungus do not give rise to the red-coloured compound.

Histological investigations of red parts of the hypocotyls showed that the red substance is located in the vascular bundles, the spiral vessels of the protoxylem being coloured red to brownish-red. At present it is not known with certainty, however, whether the cell walls or the cell contents are coloured.

\section{Purification and Characterization of the Pigments}

Thin-layer chromatography of crude extracts from infected cucumber seedlings showed the presence of at least five related pigments. The u.v. absorption spectra of the red pigments are similar to the spectra of the elsinochromes ${ }^{2}$ except for a bathochromic shift of the absorption maxima of about $20 \mathrm{~nm}$.

Throughout this investigation, ethyl acetate was used for the extraction of the pigments. The residue after evaporation of the ethyl acetate was treated with light petroleum. The phenolic fraction of the petroleum-insoluble material was then chromatographed on calcium hydrogen phosphate chromatoplates. The chromatograms after development with a benzenechloroform mixture showed five clearly distinguishable red bands. The first (fastest moving), the second and the fourth band contained only traces of red pigment. The material in the third band amounted to about 10 per cent of the mixture. The major pigment, about 85 per cent of the mixture, was present in the broad fifth band. Besides these red pigments a small amount of violet, presumably polymerized, material was present.

The major pigment, for which we propose the name cladochrome $A$, and the material isolated from the third band on the chromatograms have been obtained in a crystalline form by rechromatography on calcium hydrogen phosphate plates and crystallizations from etheracetone-light petroleum mixtures.

Cladochrome A melts at $197-199^{\circ}$ after softening at $194^{\circ}$. Microanalyses and molecular weight indicate the formula $\mathrm{C}_{38} \mathrm{H}_{42} \mathrm{O}_{14}$ with four methoxyl groups. The compound dissolves with a deep green colour in dilute sodium hydroxide, from which it can be isolated unchanged after acidification. However, when an alkaline solution is left for several hours at room temperature extensive decomposition occurs. In an organic solvent, the compound slowly decomposes under the influence of light. A solution of the compound in ethanol which was left for 2 weeks in sunlight had turned yellow. Reductive acetylation gives a bright yellow solution with a green fluorescence. When this solution is treated with alkali with access of air the colour is changed to dark green and after acidification the original red colour returns. The i.r. spectrum shows absorption bands at 1724 and $160-8 \mathrm{~cm}^{-1}$ which we assign to aliphatic

1 A. Kaurs Suresteun and C. W. Plunoers, Mededel. Landbouwhogeschool Opzoekingsstat. Staat Gent 27, 1199 (1962).

2 T. J. Batrerham and U. Weiss, Proc. Chem. Soc. 1963, 89; W. H. L. Hackenc, H. Copier and C. A. Salemink, Rec. Trav. Chim. 82, 322 (1963); U. Weiss, H. Ziffer, T. J. Batterham, M. Blumer, W. H. L. Hackeng, H. Copier and C. A. Salemink, Can. J. Microbiol. 11, 57 (1965). 
carbonyl groups and to the carbonyl groups of a hydrogen-bonded extended quinone system, respectively.

This evidence, together with the u.v. absorption spectra reproduced in Fig. 1, points to a close relationship with the elsinochromes. The NMR spectrum can be interpreted in terms of the interconverting tautomeric structures $\mathrm{Ia} \rightleftharpoons \mathrm{Ib}$, in which the position of the four methoxyl groups is left indeterminate. The interpretation of the NMR data given in Table 1 was confirmed by double resonance experiments. Irradiation at $8.9 \tau$ leads to a simplification of the multiplet at 4.98-5.33 $\tau$. A quadruplet is formed with $\mathrm{J}=10 \mathrm{c} / \mathrm{s}$ and $\mathrm{J}=2.5 \mathrm{c} / \mathrm{s}$. On the other hand by irradiation at $5 \tau$ the doublet at $8.9 \tau$ is transformed to a singlet, and the $2.5 \mathrm{c} / \mathrm{s}$ coupling at $6.52 \tau$ disappears. Irradiation around $7 \tau$ leads to the following changes in the spectrum: (a) the signal of the methyl groups at $9.35 \tau$ now becomes a singlet; $(b)$ the $13 \mathrm{c} / \mathrm{s}$ coupling $\mathrm{J}_{\mathrm{H}_{\hat{A}}-\mathrm{H}_{\mathbf{z}}}$ disappears; (c) the multiplet around $5 \tau$ sharpens up to a slightly broadened quadruplet. Finally, irradiation at $6.52 \tau$ gives a less-complex multiplet at 6.8-7.3 $\tau$. The difference in chemical shift of atoms $H_{A}$ and $H_{B}$ may be the result of the neighbouring asymmetric centre ${ }^{3}$ or of the conformation of the molecule.<smiles></smiles>

(Ia)

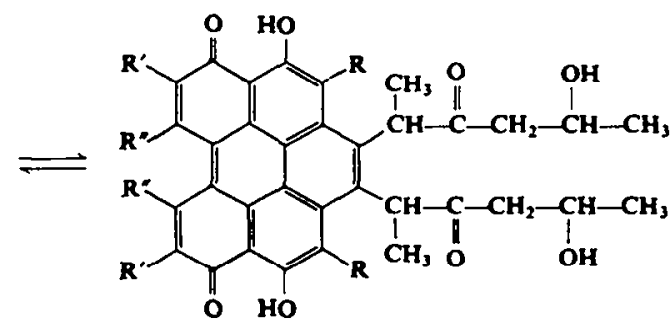

(Ib)

I.1: $R=H ; \quad R^{\prime}=R^{*}=O_{3} C_{3}$
I.2: $R^{\prime}=H ; \quad R=R^{*}=O C H_{3}$

I.3: $R^{-1}=\mathrm{H} ; \quad R=R^{\prime}=\mathrm{OCH}_{3}$

In a methylation experiment cladochrome $A$ behaves similarly to elsinochrome although the presence of the alcoholic hydroxyl groups in the side chains gives an extra complication. A solution of the compound in chloroform was shaken with silver oxide and methyl iodide. The course of the reaction was followed by thin-layer chromatography on calcium hydrogen phosphate in benzene-chloroform. Firstly, two new red spots appeared which moved faster than the starting material. These were regarded as monomethyl ethers. After shaking overnight these spots had disappeared. A chromatogram of the solution then showed the presence of at least nine products. The fastest-moving yellow compound was followed by a red and a bluish-grey band. This picture was repeated twice on the chromatogram, the last bands being very weak. The bluish-grey products represent a very small fraction of the total product. They have not been investigated further. The yellow and the red compounds must be considered as derivatives of Ia and $\mathrm{Ib}$ in which both the phenolic hydroxyl groups have been methylated. The visible spectra of the red ethers resemble the spectrum of cladochrome $A$. The fastest-moving red ether has an absorption maximum at $472 \mathrm{~nm}$ and inflections at $\lambda=560$ and $580 \mathrm{~nm}$. The second red ether has $\lambda_{\max }=468 \mathrm{~nm}$ and

3 E. J. SNYDER, J. Am. Chem. Soc. 85, 2624 (1963). 


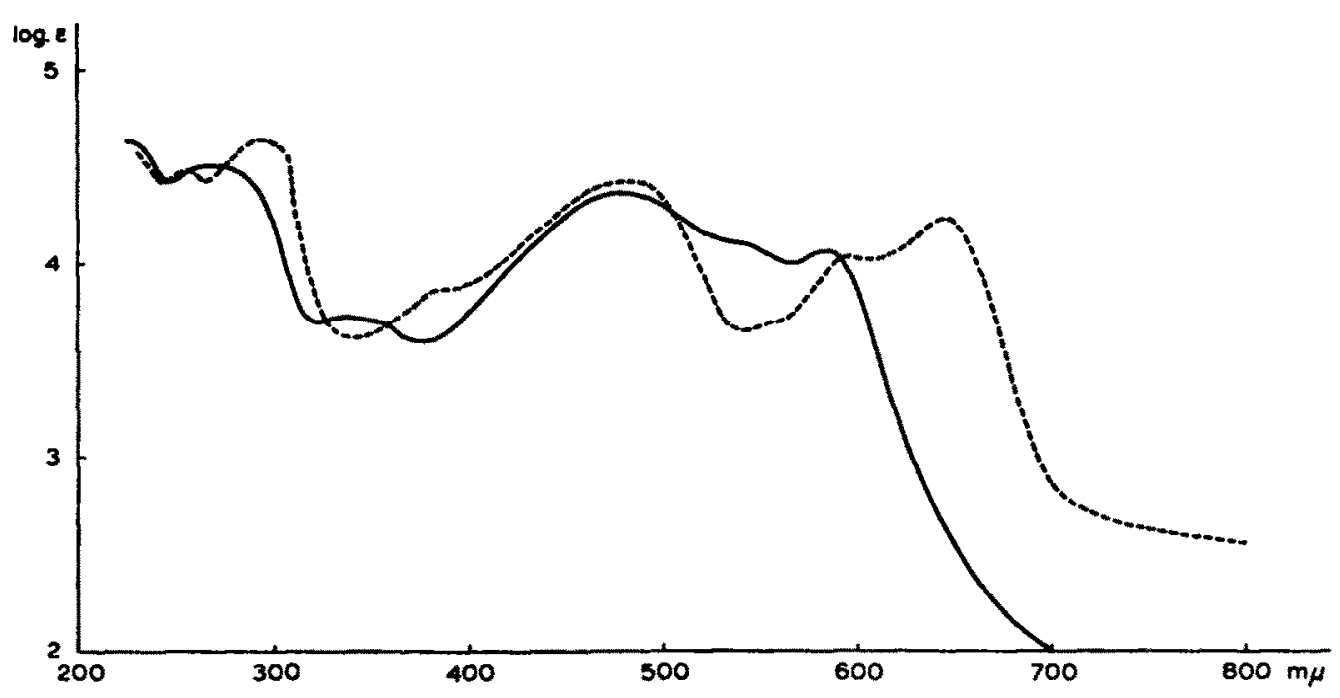

Fig. 1. Ultraviolet ABgorption SPECTRA OF CLADOCHROME A IN ETHANOL (-) AND IN 0.02 N ETHANOLIC SODIUM HYDROXIDE (-m--).

TABLE 1

\begin{tabular}{|c|c|c|c|}
\hline$r$ & Assignment & Amount of protons & $\begin{array}{c}\text { Shape of resonance } \\
\text { signal }\end{array}$ \\
\hline-5.6 & Hydrogen-bonded phenolic $\mathrm{OH}$ & 2 & Singlet \\
\hline $3 \cdot 41$ & Aromatic ring proton & 2 & Singlet \\
\hline $4 \cdot 98-5 \cdot 33$ & $-\mathrm{CH}-\mathrm{C}_{\mathrm{\theta}}^{\mathrm{OH}}-\mathrm{CH}_{3}$ & 2 & Multiplet \\
\hline $5 \cdot 75$ & $-\mathrm{OCH}_{3}$ & 6 & Singlet \\
\hline 5.95 & $-\mathrm{OCH}_{3}$ & 6 & Singlet \\
\hline \multirow[t]{3}{*}{6.52} & $\stackrel{\mathrm{O}}{\mathrm{C}}-\mathrm{CH}_{\mathrm{B}}^{\mathrm{H}}-\mathrm{CH}_{\mathrm{H}}^{\mathrm{OH}}-$ & $2 \mathbf{H}_{\mathbf{A}}$ & Quadruplet \\
\hline & & & $\mathrm{J}_{\mathrm{H}_{\mathrm{A}}-\mathrm{H}_{\mathbf{2}}}=13 \mathrm{c} / \mathrm{s}$ \\
\hline & & & $J_{H_{A}-H_{X}}=2.5 \mathrm{c} / \mathrm{s}$ \\
\hline \multirow[t]{3}{*}{$6 \cdot 8-7 \cdot 3$} & $\begin{array}{l}\mathrm{O} \\
-\stackrel{C}{C}-C_{I_{x}}^{H}-C_{\mathbf{H}_{\mathbf{x}}}^{\mathrm{OH}}-\end{array}$ & $2 \mathrm{H}_{\mathrm{B}}$ & Multiplet \\
\hline & & & $J_{H_{3}-H_{x}}=10 \mathrm{c} / \mathrm{s}$ \\
\hline & $\begin{array}{ll}\mathrm{CH}_{3} & \mathrm{O}\end{array}$ & & \\
\hline $6 \cdot 8-7 \cdot 3$ & $-C_{\theta}-\stackrel{C}{C}$ & 2 & Multiplet \\
\hline 7.7 & $-\mathrm{CH}_{\mathrm{H}}^{\mathrm{H}}-\mathrm{C}_{\mathrm{H}}^{\mathrm{O}}-\mathrm{CH}_{3}$ & 2 & Broad signal \\
\hline $8 \cdot 9$ & $-\mathrm{C}_{\mathrm{H}}-\mathrm{C}_{\mathrm{H}}^{\mathrm{H}}-\mathrm{CO}_{3}$ & 6 & Doublet, $J=6 \mathrm{c} / \mathrm{s}$ \\
\hline $9 \cdot 35$ & $\begin{array}{c}C \Theta_{3} \quad \mathrm{O} \\
\stackrel{C}{\mathrm{C}}_{\mathrm{n}}-\stackrel{\|}{\mathrm{C}}-\end{array}$ & 6 & Doublet, $\mathrm{J}=6 \mathrm{c} / \mathrm{s}$ \\
\hline
\end{tabular}


inflections at $\lambda=560$ and $580 \mathrm{~nm}$. The two fastest-moving yellow ethers exhibit absorption maxima at $\lambda=442$ (first ether) and $\lambda=447 \mathrm{~nm}$ (second ether).

From the hydroxyl absorptions in the i.r. spectra it can be concluded that in the fastestmoving yellow and red ethers the alcoholic hydroxyl groups are also methylated. In all products the aliphatic carbonyl groups are left intact $\left(\nu_{\max }=1727 \mathrm{~cm}^{-1}\right)$. The quinone carbonyls absorb at $1629 \mathrm{~cm}^{-1}$ in the yellow ethers and at $1621 \mathrm{~cm}^{-1}$ in the red ethers.

Structure $\mathrm{I}, \mathrm{C}_{38} \mathrm{H}_{38} \mathrm{O}_{12}$, is not in accordance with the microanalytical data which lead to the true formula $\mathrm{C}_{38} \mathrm{H}_{38} \mathrm{O}_{12} \cdot 2 \mathrm{H}_{2} \mathrm{O}$. However, it is known that compounds of this type tenaciously hold molecules of solvent in the crystalline state. It is possible that the crystals used for the microanalyses, despite the drying in a high vacuum, contained 2 moles of water. A micro Kuhn-Roth determination gave the high value of $4.8 \mathrm{C}^{\left(\mathrm{CH}_{3}\right)}$ groups per molecule. If formula I is correct, it has to be assumed that in addition to the expected 4 moles of acetic acid a little more volatile acid is formed in the oxidative breakdown of cladochrome $A$.

\section{Fungitoxicity}

Cladochrome $A$ was incorporated in glucose mineral salts agar, $\mathrm{pH} 6.5$, which was then seeded with spores of the fungi Botrytis allit, Penicillium italicum, Aspergillus niger or Cladosporium cucumerinum according to methods earlier described. ${ }^{4}$ In the presence of $0.01 \%$ of the compound growth was normal, indicating that this concentration is not fungitoxic.

\section{Discussion}

The accumulated evidence leaves no doubt about the close structural relationship of the cladochromes with the elsinochromes. The microanalytical and spectral data allow us to make the reasonable proposal of structure I for cladochrome A. Much work remains to be done, however, to establish structure I with certainty and to determine the structures of the other cladochromes, the more so since the isolation of these compounds in larger amounts is a lengthy and cumbersome procedure.

Since it appears at the moment that a more complete knowledge of the structure of the cladochromes would not lead to a better insight either into the course of the disease development or into the causes of resistance or susceptibility, we have refrained from further work on the structure of the cladochromes.

Since the elucidation of the structure of the aphin pigments by Todd and his co-workers 5 several reports on related natural pigments have been recorded in the literature. Recently Butler $e t$ al. ${ }^{6}$ have accumulated evidence for the occurrence of a chlorinated dihydroxyperylenequinone in an Australian soil sample in which decomposed roots of an Eucalyptus species were present. The elsinochromes, ${ }^{2}$ like the pigments of Daldinia concentrica, ${ }^{7}$ are produced by fungi. Cercosporin ${ }^{8}$ is produced by the fungus Cercosporina Kikuchii Mats. causing the so-called "Soy bean purple speck disease". The cladochromes are remarkable compounds in view of the fact that for their production the interaction of two organisms is necessary. The fact that they are only produced in etiolated plants after infection with Cladosporium cucumerinum and not under normal conditions of attack by this fungus or by other fungi, as

4 C. W. Pluloers and A. KaArs Suptotein, Amn. Appl. Biol. 57, 465 (1960).

3 A. R. Todd, Experientia 18, 433 (1962).

6 J. H. A. Butuer, D. T. Downing and R. J. Swavy, Australian J. Chem. 17, 817 (1964).

7 D. C. Alupont and J. D. Bu'Lock, J. Chem. Sac. 1958, 4090.

S. KuYaMA, J. Org. Chem. 27, 939 (1962). 
well as the observation that at least the main compound is not fungitoxic, rules out the possibility that they could play a role as phytoalexins.9

In view of the still unknown pathways of biosynthesis of the cladochromes the observation of Engelsma and Meyer, and Engelsma ${ }^{10}$ that differences exist in the polyphenolic content of etiolated and green cucumber seedlings is worthy of note.

\section{EXPERIMENTAL}

\section{Isolation of Cladochromes}

Infected seedlings grown from $100 \mathrm{~g}$ of seed were extracted twice with boiling ethyl acetate. After filtration the ethyl acetate layer was washed with aqueous sodium chloride and dried $\left(\mathrm{Na}_{2} \mathrm{SO}_{4}\right)$. It was then evaporated in vacuo and the dark-red oily residue was shaken with light petroleum. After standing for some hours the petroleum layer was decanted from the tar which had settled on the wall of the vessel. The tar was then dissolved in $0.1 \mathrm{~N} \mathrm{NaOH}$. The dark-green solution was rapidly extracted with an excess of ether. The ether was discarded and the aqueous layer immediately acidified with $\mathrm{HCl}$. The red oily material which separated was then taken up in ether. The ethereal solution was washed with aqueous $\mathrm{NaHCO}_{3}$ and with water. After drying $\left(\mathrm{Na}_{2} \mathrm{SO}_{4}\right)$ the solution was evaporated.

The weight of the residue varied in several experiments between 30 and $100 \mathrm{mg} . E_{1 \mathrm{~cm}}^{1^{\circ}}$, at $478 \mathrm{~nm}$ in ethanol, was found in different experiments to lie between 105 and 160 .

Further purification was effected by preparative thin-layer chromatography on calcium hydrogen phosphate. Commercial $\mathrm{CaHPO}_{4} \cdot 2 \mathrm{H}_{2} \mathrm{O}$ was dehydrated over a free flame and stored in a desiccator. Chromatoplates were simply prepared by pouring a suspension of $\mathrm{CaHPO}_{4}$ in chloroform over the glass surface. The plates were allowed to dry at room temperature and used immediately.

Separation of the cladochromes was generally effected with benzene-chloroform, 2:1. However, $R_{f}$ values are highly dependent on temperature and on the water content of the $\mathrm{CaHPO}_{4}$. With very dry $\mathrm{CaHPO}_{4}$ and at a low room temperature, separation was better when the chloroform content of the solvent was higher. The bands were extracted from the plate with acetone and rechromatographed. Cladochrome $A$ was finally dissolved in ether containing a drop of acetone. Subsequently, light petroleum was cautiously added until the solution became slightly turbid. After standing overnight the pigment had crystallized. The crystals were dried over $\mathrm{P}_{2} \mathrm{O}_{5}$ at $80^{\circ}$ in a high vacuum. M.p. $197-199^{\circ}$ after softening at $194^{\circ}$. E $E_{1 \mathrm{~cm}}^{1 \%}$ at $478 \mathrm{~nm}: 315$. Analyses of different batches:

Found: $\mathrm{C}, 63 \cdot 26,62 \cdot 90 ; \mathrm{H}, 5 \cdot 92,5 \cdot 77 ; \mathrm{O}, 30 \cdot 81 ; \mathrm{OMe}, 16 \cdot 16 ; \mathrm{C}(\mathrm{Me}), 9 \cdot 88,9 \cdot 98$.

Calc. for $\mathrm{C}_{38} \mathrm{H}_{38} \mathrm{O}_{12} .2 \mathrm{H}_{2} \mathrm{O}: \mathrm{C}, 63 \cdot 15 ; \mathrm{H}, 5 \cdot 86 ; \mathrm{O}, 30.99 ; 40 \mathrm{Me}, 17 \cdot 18 ; 4 \mathrm{C}(\mathrm{Me}), 8.32 \%$.

Mol.wt. (osmometric in benzene): Found: 712; Calc. for $\mathrm{C}_{38} \mathrm{H}_{42} \mathrm{O}_{14}: 722.7$.

During this work about $8 \mathrm{mg}$ of the second major pigment have been obtained in a crystalline form. Analysis : C, 66.01; H, 5.89; OMe, 16.64\%. $100 \mathrm{Mc}$ NMR spectra have been recorded in deuterochloroform with tetramethylsilane as an internal standard. Infrared spectra were taken in $\mathrm{KBr}$ disks.

\section{Reductive Acetylation}

A few milligrams of cladochrome A were dissolved in acetic anhydride. Zinc powder and subsequently a drop of diethylamine were added. The yellow, strongly fluorescing solution

9. A. M. Cruickshank, Ann. Rev. Phytopath. 2, 351 (1963).

10 G. Engezsma and G. MeYer, Acta Bot. Neerl. 14, 54 (1965); G. Engelsmu, Nature 208, 1117 (1965). 
was filtered and poured into water. The product was extracted with ether. Absorption maximum in ethanol at $474 \mathrm{~nm}$.

\section{Methylation}

$80 \mathrm{mg}$ cladochrome A were shaken with $25 \mathrm{ml}$ of dry chloroform, $2 \mathrm{~g}$ of freshly prepared silver oxide and $2 \mathrm{ml}$ of methyl iodide. The course of the reaction was followed by thin-layer chromatography. After $24 \mathrm{hr}$ the reaction was stopped.

Products were separated on $\mathrm{CaHPO}_{4}$ plates with benzene-chloroform, 2:1. The bands of the first (fastest moving) and second yellow ethers and of the first and second red ethers were rechromatographed. Ultraviolet spectra of the chromatographically pure compounds were taken in ethanol, i.r. spectra were recorded in $\mathrm{KBr}$ disks.

The ethers have been obtained as amorphous powders. Only the second yellow ether $(6 \mathrm{mg})$ could be crystallized from ether-petroleum ether. M.p. 179-180 .

Acknowledgements-The authors are indebted to Dr. U. Scheidegger of Varian A.G. Zuirich, for recording the $100 \mathrm{Mc}$ NMR spectrum of cladochrome $A$ and for carrying out the double resonance experiments. They are grateful to Professor Dr. G. J. M. van der Kerk, Mr. J. W. Marsman and Dr. W. Drenth of this Institute for their interest and for belp with the interpretation of spectral data. 